\title{
The Role and Analyses of Medical Insurance Services in the Development of the National Insurance Market. Case of Uzbekistan
}

\author{
Zakirxodjayeva Shirin \\ Toshkent Financial Institute
}

\begin{abstract}
This paper makes investigation on the The role and analyses of medical insurance services in the development of the national insurance market. Research was conducted in the case of Uzbekistan and analyzed the basis of the theoretical background implemented with examples. Finally, research data with outcomes and shortcomings were stated in order to open the doors of the further research opportunities in the future.

Keywords: medical insurance, insurance services, national insurance market, Uzbekistan.

DOI: $10.7176 / \mathrm{EJBM} / 11-16-02$

Publication date:June $30^{\text {th }} 2019$

\section{Introduction}

To date, we can say with confidence that insurance is an important component of the economy of our country. The complex of measures carried out in connection with the further development and reform of the insurance market, in particular, its important component in improving the insurance legislation, is primarily aimed at maximizing coverage of the population with insurance. In this way, its social protection is ensured, the confidence of the population in insurance organizations is strengthened, which ultimately raises the interests of consumers of insurance services to the first level(Khodjaeva, Kharabara, \& Akhmedov, 2001; Pistrick \& Mal'cev, 1998; Razakov Sh \& Shakhgunova, 2001).

One of the main decisions aimed at radically changing the insurance market was the decision of the president of the Republic of Uzbekistan "on measures for further reform and development of the Insurance Services Market"adopted on 10 April 2007. With this decision, the program of reform and development of the insurance market of the Republic of Uzbekistan for 2007-2010 was approved, according to which, along with other legal documents, the adoption of the law of the Republic of Uzbekistan "on medical insurance"was envisaged.

This is due to the fact that to date, the issues of medical insurance are not regulated by a separate normative act. In this regard, after the adoption of a separate law on this insurance, it is envisaged to restore the legal basis for the implementation of voluntary and compulsory medical insurance. Today, voluntary health insurance is more developed than in the first years of independence - the number of insurance companies providing voluntary health insurance services has increased, accordingly, the main indicators of medical insurance are also gradually increasing, the quality of insurance services rendered by this type of insurance is increasing(Bassolas, Lenormand, Tugores, Gonçalves, \& Ramasco, 2016; Razakov Sh \& Shakhgunova, 2001; Schulze, 2009).
\end{abstract}

\section{Research background}

Now we will dwell on the existing system of voluntary health insurance in the Republic. Despite the fact that in the market of Insurance Services, low-number companies with voluntary medical insurance are engaged, the conditions and mechanism for providing such services practically do not differ from each other. In the provision of medical insurance services, insurance companies use the services of assistant companies. The main task of assistant companies is an expression from the organization of medical services to insured persons through medical institutions. To do this, the assistant companies must organize the reception of continuous reports from the insurers (insured persons) about insurance events day and night, as well as the provision of necessary assistance to the insurers (insured persons) on the basis of the insurance policy provided under the insurance contract. Such a request for assistance companies is established by Article 9-9 of the law of the Republic of Uzbekistan "on insurance activity".

Sometimes it is considered that medical insurance is a personal matter, in insurance the interest associated with the personality of the insured person and not with the property is insured. However, this is a mistake. In medical insurance, the interests of the insured person in relation to the damage delivered to him by the disease, which is subject to additional costs, are insured . If a person did not get sick, it would not have cost either. Therefore, medical insurance is a kind of property of insurance. But a special feature of medical insurance in relation to other types of property insurance is that the insurance payments will not have the character of the divided damage delivered, but they will prevent this damage, since the cost of treatment will be paid by the insurer instead of the insured person. In this type of insurance, it is said that the insured person, as an insured event, must apply to the medical institution, requiring the provision of medical services during the insurance period. Bunda should be 
informed that the client's health is damaged by such causes as an unfortunate event, acute illness or chronic illness (except for the stipulated exceptions). As a result, the insurer is obliged to pay the amount of insurance for medical services rendered to the insured person and the insurance payment within the limit.

As mentioned earlier, the declaration on the state of Health is used to assess risks in Uzbekistan. If the insured person shows that there is a certain chronic illness in this declaration, the coefficient increasing to the basic insurance premium is applied. Important factors such as the age of the insured person, the insurance program, the amount of insurance and of course the period of insurance play a key role in determining the amount of insurance premium. However, if it is necessary to insure a large number of insured persons, the age criterion is usually not taken into account (Bramwell, 2005; Turner \& Freiermuth, 2017).

\section{Data analyses}

The insurance program can provide for the coverage of certain expenses of the insured persons in connection with the provision of the following services:

* Outpatient-Polyclinic service;

- Calling a doctor home;

- Fast and emergency medical care;

* Stationary maintenance;

* Provision of medicines during outpatient services;

* Emergency emergency dental care;

- Vaccination;

* Medical examination;

- Medical evacuation etc.

The costs associated with pregnancy and the birth of a child are not provided for in standard insurance contracts and are included in the category of exceptions. It should be noted here that such exceptions affect the health system, for example, the birth of a child or the treatment of infectious diseases in Uzbekistan is free of charge, which serves as the basis for the exclusion of these phenomena. In addition, the insurance premium is also established for citizens of the Republic of Uzbekistan in a smaller amount than for non-citizens. This is due to the fact that prices in medical institutions are assigned separately for citizens and guests of our country.

The mechanism for accepting this or that person for insurance, that is, the sale of a voluntary medical insurance policy and the provision of services for an insurance policy, is carried out in the following order:

When concluding a contract, the insured person fills out a declaration on the state of Health. This document answers certain questions (for example, "Have you ever had a chronic illness?") is a one-page questionnaire, according to which the insurer determines the health status of the insured person and the risks that are acceptable for insurance. If more than one person (more than ten people) is insured, depending on the specific situation, the insurer may not require filling out a declaration on the state of Health. When the insurance contract is signed and the insurance premium arrives, the insurer sends a Bordero to the assistant service. The information that must be indicated on the border includes the full name of the insured person, the order number of the insurance policy, the insurance program, the term of the insurance and the terms of the contract.

\section{Structure and policy of the medical insurance. Case of Uzbekistan.}

The insured person will apply to the assistant service in case of illness. The assistant service determines whether the appeal of the insured person should be an insurance event. In the event of a positive decision, the coordinators give the insured person a ticket to the medical institution in which he or she has concluded an agreement with the insurer on the provision of medical services. In this medical institution, a certain amount of medical services are provided to the insured person. The insured person must provide the insurance policy and identity document when he comes to the medical institution(Lal, Suleimenov, Stewart, \& Hansen, 2007; Universidade Taubaté Mestrado em Gestão e Desenvolvimento Regional, Grotta, \& Junior, 2010).

After providing the necessary services to the insured person, he signs a special form, which is a document confirming the provision of services on a specified scale. The medical institution provides the accounts for medical services rendered to the insured person to the assistant service. The assistant service in turn (for example, after making the payment independently) delivers it to the insurer. After checking the compliance of the provided services with the terms of the voluntary medical insurance contract, the insurer makes payments on the accounts in accordance with the established procedure.

Usually, on voluntary medical insurance, direct payments and reimbursements are not made by the insurer to the insured person, so there are no problems with the delay in payment or reimbursement.

The implementation of direct payments (compensation) to the insured person began in Uzbekistan for the first time by the insurance company "Transinsurance Plus". In particular, as indicated separately in the rules of voluntary medical insurance, if the insured person for some reason can not apply to the service of the assistant, he can apply directly to the medical institution, use medical services, and then provide accounts for the payment of 
the corresponding payments to the insurer. One can see by guessing what the pros and cons of such a system will be.

A positive aspect of this is that insured persons can apply directly to medical institutions and use medical services. This is a very favorable opportunity, because it is not known what kind of illness the insured person will suffer and whether he will be in a situation where he will apply for an assistant service at that time (for example, if an unfortunate event occurs, witnesses of the incident will deliver him to an emergency medical institution and will absolutely not know that case ).

The downside of this system is that it will be difficult for the insurer to determine whether this event was an insurance event, which in turn will give him an increase in the amount of work that he may have done and hard.

Such an operation does not happen every day, therefore, today it is possible only to find and determine the insured person from the data ombor of the assistance service, and only in time (for example, because the insurer did not deliver the border to the assistant service on time, because of technical errors in the input of data ombor into the data ombor of the And the insured person can plan his time and go to the medical institution at the appointed time and wait until the doctor accepts another patient. Here the fault can be in the doctor who has forgotten the insured person or in the assistant service coordinator, but in any case the main fault will be in the assistant service, which has not taken the process under his control.

1) Insecurity of the population in general to the insurance and the fact that it is possible to use a good medical service, and even its minimum package guaranteed by the state.

2) inconvenience associated with the existing mechanism of providing services in the insurance policy, in particular with the application to the assistant service.

3 ) the quality of the services offered is largely due to the complexity of controlling the process of providing services to the insured person. In other words, in the presence of the provision of services in the insurance policy, the insurer does not have the opportunity to control the entire process from the moment when the insured person applies to the medical institution, to the moment when the relevant (exactly the necessary) services are rendered to him. As a rule, employees of a medical institution are faced with cases when, in addition to the necessary medical services to the insured person, they also carry out additional procedures that are not necessary for him.

4) the lack of demand for voluntary health insurance, that is, this service is not widely popular, therefore, insurance agents are also not interested in selling only voluntary health insurance policies. However, it should be noted that if the insured person is serviced by an insurance policy, usually he or she will also pay the validity period of the voluntary health insurance policy for the next period.

5 ) it is also necessary to mention the sub-problems of this system. Insurers do not include medical institutions in the list of medical institutions in the budget account, since the level of remuneration for labor in them is much lower than in private clinics. Lasa even in the work of highly qualified personnel in such hospitals, "cash settlements"you can not use full-fledged medical services, because the assistant service can not work with such institutions.

6) due to low demand for voluntary medical insurance as well as lack of sufficient statistics, it is not possible for insurers to real assess the risks that are accepted for insurance. As a result, the errors in the accounts of insurers are relatively high. When concluding an insurance contract in European and Western countries, insurers first conduct a medical examination of the insured person in order to determine the health status. The amount of this insurance premium is even affected by the sex of the insured person, his smoking-free, his lifestyle, etc., while our national insurers do not necessarily pay attention to this.

There is no normative-legal framework regulating voluntary health insurance. There are no specific additional benefits granted only to insurers engaged in voluntary health insurance (note: today a number of benefits have been introduced, aimed at faulting the activities of insurers with various decisions of the head of state and the government of the country).

It's no secret that today there are a lot of problems in the health system. This is a problem both with the material and technical equipment of medical institutions, and with the quality of services provided, and with the qualification of medical personnel. It is also necessary to remember the sub-factor (based on the individual approach).

Modern methodology and technology as well as financial resources and state support are lacking for effective functioning of voluntary health insurance.

First, as already mentioned above, there is no normative-legal framework that defines the basic requirements for the voluntary health insurance system, the rights and obligations of the parties, as well as the basic conditions for the implementation of voluntary health insurance, single definitions (for example, what is included in outpatient services or what is understood when a medical examination says).

Secondly, from the point of view of technology, the existing mechanism of providing services for the insurance policy does not meet the requirements of real reality. According to the factual assessment given to the situation by our non-resident friends, assistance services are not the most effective way to carry out voluntary medical insurance. Yes, the assistant service is an international experience, "but this is to some extent, partly true." 
But the operating assistant companies absolutely do not meet international standards, they do not have the speed of service, the qualification of service operators is low. Such operators should be highly qualified medical personnel, they should not only understand the condition of the insured persons to whom they apply, but also be able to make an approximate diagnosis and send the client to the clinic of the desired specialty. In fact, in the positions of such an operator work mainly students who want to generate additional income in their spare time from studying, studying in medical universities. Of course, calling an assistant service is also like calling a medical institution or calling an ambulance. However, it is not known how quickly to call an ambulance or a doctor at home through the help service.

The technology of carrying out voluntary medical insurance should be established so that access to a medical institution is free, that is, for this the insured person does not have to show the insurance policy and the document confirming the person. Perhaps, instead of the standard A4 size insurance policyholders, the transition period to the plastic card system, which can be used in any medical institution, when the case is connected, is indicated by the insurance terms (program).

\section{Discussion}

Current state and growth trends of implementation of medical insurance in Uzbekistan. The provision of voluntary medical insurance services in Uzbekistan is largely unprofitable. However, insurance companies introduce and develop this type of insurance with the aim of expanding their range of services, because it attracts corporate customers. A customer who is satisfied with the quality of services provided by one type of insurance, will also willingly purchase other types of services of this company. Therefore, insurance companies finance losses from voluntary medical insurance to the account of other types of insurance and other types of activities.

\section{Conclusion}

There are a lot of specific positive aspects of the implementation of medical insurance in Uzbekistan, at the same time, it is important to understand the same positive aspects by demonstrating the current state of their application to the population in practice. But in the insurance market of our country, statistics on the implementation of medical insurance are not published in the press or on the site of insurance companies, and this situation undermines the interest in medical insurance. On the contrary, it is necessary to show on the internet sites, through various portals and the press, so that the process of introduction of compulsory medical insurance also accelerates.

\section{References}

Bassolas, A., Lenormand, M., Tugores, A., Gonçalves, B., \& Ramasco, J. J. (2016). Touristic site attractiveness seen through Twitter. EPJ Data Science, 5(1). https://doi.org/10.1140/epjds/s13688-016-0073-5

Bramwell, B. (2005). Global Tourism. Global Tourism, 406-425. https://doi.org/10.1016/B978-0-7506-77899.50030-3

Khodjaeva, D. N., Kharabara, G. I., \& Akhmedov, S. A. (2001). Suicide prevention in Uzbekistan. Mental Health Reforms, 6(2), 16-17.

Lal, R., Suleimenov, M., Stewart, B., \& Hansen, D. (2007). Climate change and terrestrial carbon sequestration in Central Asia.

Pistrick, K., \& Mal'cev, I. I. (1998). Expedition to the south-western Hissar Mountains (Southern Uzbekistan) for collecting plant genetic resources in 1995. Genetic Resources and Crop Evolution. https://doi.org/10.1023/A:1008613715541

Razakov Sh, A., \& Shakhgunova, Gs. (2001). [Current malaria situation in the Republic of Uzbekistan]. Med Parazitol (Mosk), (1), 39-41. Retrieved from http://www.ncbi.nlm.nih.gov/pubmed/11548313

Schulze, G. (2009). Journal Rankings for Economics and Business Administration. Working paper.

Turner, R., \& Freiermuth, E. (2017). Travel \& Tourism Economic Impact 2017: Portugal. World Travel \& Tourism Council. Retrieved from https:/www.wttc.org/-/media/files/reports/economic-impact-research/countries2017/portugal2017.pdf

Universidade Taubaté Mestrado em Gestão e Desenvolvimento Regional, P. A., Grotta, R. C., \& Junior, C. M. (2010). Latin American journal of business management: LAJBM. Latin American Journal of Business Management (Vol. 8). Retrieved from http://lajbm.com/index.php/journal/article/view/432 